\title{
Selective Shut-off Strategy in Distributed Battery Systems
}

\author{
M. Kubilay Özgüçç ${ }^{*}$, Kadir Aras ${ }^{1}$ \\ 0000-0002-6636-0733', 0000-0001-6424-0837²
}

${ }^{1}$ AVL Research and Engineering Turkey, Istanbul, 34885, Turkey

\section{Abstract}

Rapid development in electric mobility raise distance anxiety. Thus, high capacity systems with high efficiency are offered as a solution. However, the capacity of the system is limited by the available space in the vehicle. To outcome this problem, the parallel distributed battery system is presented especially for heavy-duty vehicles like buses and trucks. Having a parallel distributed structure brings the necessity of providing a safety strategy not only for the single pack but also for the whole system. Every single pack has al-ready its fault protection system. Whenever an electrical fault occurs in the pack, it is cleared by either a contactor or a fuse. Thus, the pack becomes out of order, therefore, the vehicle cannot continue its operation and must be trailered. By utilizing a parallel distributed battery system, vehicle continuity can be provided even after an electrical fault with a selective shut-off strategy. The presented strategy in this paper, not only provides vehicle continuity but also ensures additional safety on the system.

Keywords: Electric Vehicle, Battery Systems, Shut-off Strategy, Short-Circuit Protection
Research Article

http://doi.org/10.30939/ijastech..819912

$\begin{array}{ll}\text { Received } & 03.11 .2020 \\ \text { Revised } & 28.12 .2020 \\ \text { Accepted } & 31.12 .2020\end{array}$

* Corresponding author

M. Kubilay Özgüç

kubilay.ozguc@avl.com

Adress: Akpınar Mahallesi Tuna Caddesi, Ballıca Sk. No:1, 34885 Sancaktepe

Tel: +90216498 7952

\section{Introduction}

For the past years, the perspective of societies and governments on global warming and climate change have changed considerably. So, being in search of solutions to fight against global warming can be observed in many countries both in individual and collective ways. Using electricity as a source of energy instead of other harmful fuels is one of the known methods. Therefore, this increasing consciousness and demands of nature-friendly way outs have sped up the process in the arrival of electric vehicles, particularly in the mobility industry [1]. CO2 reduction laws, specially brought to cities, have enabled a forced conversion in public transport [2]. However, this rapid increase has brought a range anxiety to it. Improvement in energy density on cell basis is essential to prevent this perception. In $\mathrm{xEV}$ applications the smallest unit in the battery system is described as cells. In general, the chemistry is li-ion and it consists of four main parts which are cathode, anode, electrolyte, and separator [3]. The cells create the modules by connecting in series and (or) parallel. Moreover, modules form the battery system with a specific configuration. Furthermore, paralleling battery packs provides more energy content for the electrification of large vehicles such as buses and trucks [4]. This type of application provides flexibility during the design. Such systems also lead up to the usage of all unused areas in large vehicles. Using distributed battery systems (DBS) allows more capacity instead of one bulky pack. However, the system which is created by more than one battery pack shall also fulfill the functional safety requirements as a single standalone pack. A safety system is performed against fault currents in a battery pack through the alignment of the fuse and the contactor. However, since parallel packs will have a (PDU) power distribution unit where all packs are inter-connected to supply the required power to the traction, a functional safety concept shall be implemented to both the components in the (BDU) battery disconnect unit and the elements in the PDU. When the system is examined electrically through a single line diagram, the system is in the form of parallel conformity of more than one contactor-fuse pair and connecting these parallel strings to a larger contactor-fuse pair. While this is a method for general use in industrial applications [59] it is also required in automotive battery applications. However, in the literature, over current protection studies are made for only one pack system [10-14] and there is no noteworthy study done for distributed systems. In this study, a detailed analysis of the selective shut-off strategy for a parallel connected battery system is investigated. The main target is to maintain the vehicle operation properly in a failure case by cutting-off just the pack with fault instead of shutting down the whole system. Thus, the other packs can continue to provide energy and power to the traction. As a result, the alignment of contactor and fuse in the system shall be conducted properly on not only a pack basis but also a system basis.

\section{Structure of a Battery System}

In battery packs, modules are made of cells connected in parallel and (or) series. Beyond that, the pack consists of modules with 
different configurations. Moreover, to ensure the functionality and safety of the battery system as can be seen in Figure 1, there are components such as contactors, fuses, connectors, and sensors in addition to the modules $[15,16]$. Apart from these components, there are many parts with the functionality of measurement, control, and execution in the pack. Contactors serve as a switch in automotive battery packs at normal operating ranges for the make and break the battery from the vehicle powertrain and to protect against fault currents up to a certain level. Usually, two contactors are used to switch both, the positive and the negative HV path to achieve redundancy according to functional safety regulations and homogeneous switching behavior, and to assure complete galvanic isolation of the battery from the rest of the system [17]. Despite that, there is a series connected fuse for fault currents which the contactors are not capable of safely switch off. Over-current and short-circuit current protection are ensured by a fuse, where cuts off large fault currents. This fuse may be controlled or uncontrolled. Therefore, an alignment between fuse and relay is necessary to cover the whole current range in a battery system. Described areas of the interaction of relay and fuse in certain current categories are the individual "working current areas" of the components. To measure the current values in the battery pack it is necessary to specify a current sensor properly. In automotive battery packs, generally, as a current sensor shunt and hall technologies are utilized. However, in some cases, fluxgate sensors are considered. Nearly all packs have 2 current sensors to provide functional safety [17]. The first one is for measuring the current and the second sensor is for redundancy. On the other hand, if the sensor has 2 channels, it can be used as a standalone sensor to fulfill functional safety. Furthermore, these current values are read by (BMS) battery management system and the data from two sensors are compared between each other to execute contactor control signals when it is necessary. Besides, current sensors, as well as the contactors and fuses, are required to test for shock and vibration requirements for automotive applications. Moreover, all these components shall meet specific requirements regarding, volume, power loss, weight, voltage, and current.

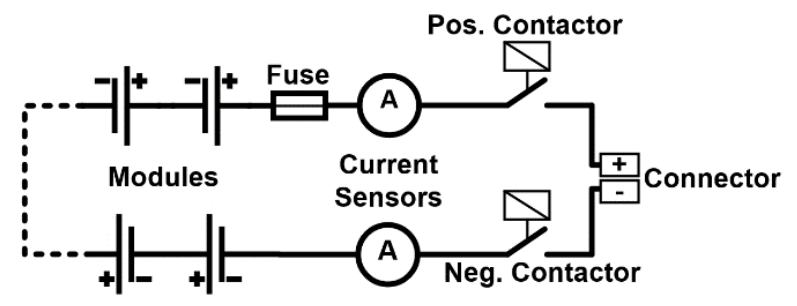

Fig. 1. Battery Pack Structure

A battery system can be made of parallel and (or) serial packages, the multiple system conjugates in the PDU to supply power to the powertrain, and same as the BDU there are several components in the PDU also, where a parallel structure can be seen in Figure 2. These components are liable to different requirements as they are positioned at the system level rather than the pack level.

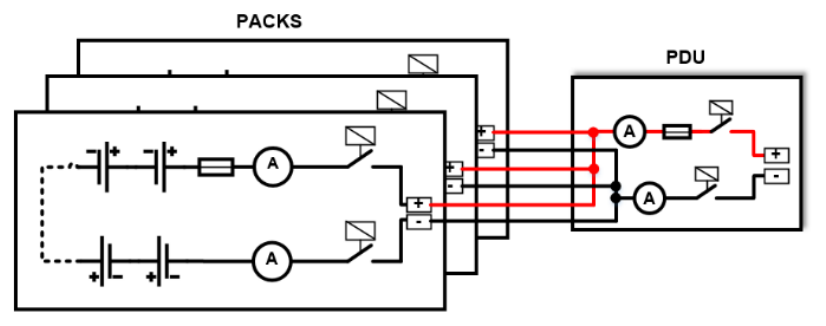

Fig. 2. Parallel Battery Pack System

\section{Definition of Shut-off Strategy}

The shut-off strategy is a safety procedure to achieve functional safety. It is designed by considering safety components' specifications and managed by BMS. That is why BDU components shall be selected according to the safety procedure. Contactors, fuses, current sensors, connectors, busbars, cables, and even adhesive isolation tapes can affect the overall system's operating performance by creating an impediment. The weakest component can cause failure. The shut-off strategy exhibits this weakest part. The core of the shut-off strategy is a proper alignment of relay and fuse. The contactor can switch off lower currents to ensure sustainability, while fuse cutting-off high currents where the relay only can carry but can't switch off. An additional safety function is the overlap of the working areas of relay and fuse. Another important part to fulfill the safety function is the battery management system in combination with the current sensors to decide in case of failure if the relays shall be kept closed and the system shall be switched off by fuse, or if the relays shall cut-off the system. As shown in Figure 3 , with the help of the I-t curves of a contactor, fuse, current sensor, and load profile, current regions are visualized. Those 4 main regions are the normal operating zone, fault current zone, the zone where the current on this circuit shall never reach, and the zone beyond the maximum short-circuit current. To create borderlines of the shut-off strategy, the contactor shall keep the circuit running within the normal operating range and the fuse shall not interact with the system shown as the green zone in Figure 3. The fault current part shall be divided into two zones, the point that separates these zones is called the strategic switching point. Furthermore, it is decided with the alignment of the fuse, contactor, and current sensors. The first one is the over-current zone, which is shown in yellow in Figure 3. In this region, the contactor deals with fault currents. Due to the fact that the contactor is like a blind shear on its own, BMS ensures that the contactor controls the correct ranges with the help of measured current values from sensors within specified tolerances. In this process, as long as the contactors have done the switching operation successfully, the fuse would not intervene in the circuit however would work as a secondary safety element in a possible contactor failure case. The second part of the fault currents shown as the red zone in Figure 3 is the region that can be defined as a short-circuit current zone. Since the error currents occurring in this region are greater than the currents that the contactor can handle, the fault currents would occur at this level would let BMS execute the command of stay open to the contactor, and the 
failure would be interrupted by the fuse. After this fault handling process, BMS reads current values through the current sensors, and when the fault current neglected, the contactors will be opened for galvanic isolation in both paths as a safety priority and then contactor and fuse failure diagnostics are made and if necessary, a vehicle will be sent to the service [18]. For the proper functioning of the system, the I-t curves and production tolerances of the components shall be embedded in the BMS algorithm to manage contactor control signals. The contactor, current sensor, and fuse shall be selected according to this system. Mechanical and environmental requirements such as vibration and shock, temperature, and humidity shall be considered during selection. Moreover, derating curves of components such as busbars, cables, and connectors that may cause problems to this system shall be examined together with a shut-off strategy development.

\subsection{Alternative Methods for Shut-off Strategy}

There are alternative methods for clearing electrical faults in the system by eliminating the contactors and the fuses. One of these methods in the market is pyro-fuses. They are chosen because of their specific feature which is controllability. This feature allows drawing borders between shut-off strategy zones much more precisely. Pyro-fuses can be presented in a system that can perform and handle its error analysis to achieve the shut-off strategy [10,
11]. Additionally, using a pyro-fuse parallel to a melting fuse is another method [12]. This method has the advantage of covering all current zones, but mismatching current between both components may create a bottleneck. Moreover, if a faster solution is needed, semiconductor technology provides an interruption of fault currents in microseconds with their advantages of solid-state structures. In order not to waste the advantages of the rapid response of the semiconductor; the measurement and control circuit shall be fast in the same way. Therefore, conventional hall and shunt measurements would not work with the semiconductor to achieve a fast short-circuit response. Thus, an analog protection circuit shall be needed for this application. Studies on these circuits prove that they can clear the fault currents in microseconds, even if all delays are included $[19,20]$. The utilization of semiconductor switches is only constricted for LV battery systems [21]. The reason behind not being used in HV battery systems is voltage switching stress and galvanic isolation requirements. However, according to recent developments, semiconductor switches have been put forward on HV battery applications as a hybrid switching method $[22,23]$. Semiconductor switches offer many advantages when compared to conventional solutions. Due to the absence of moving parts, there is no arcing, contact erosion, or bounce. Very soon, contactor, fuses, and even pyro-fuses will be replaced by semiconductor switches on HV battery applications in electric vehicles.

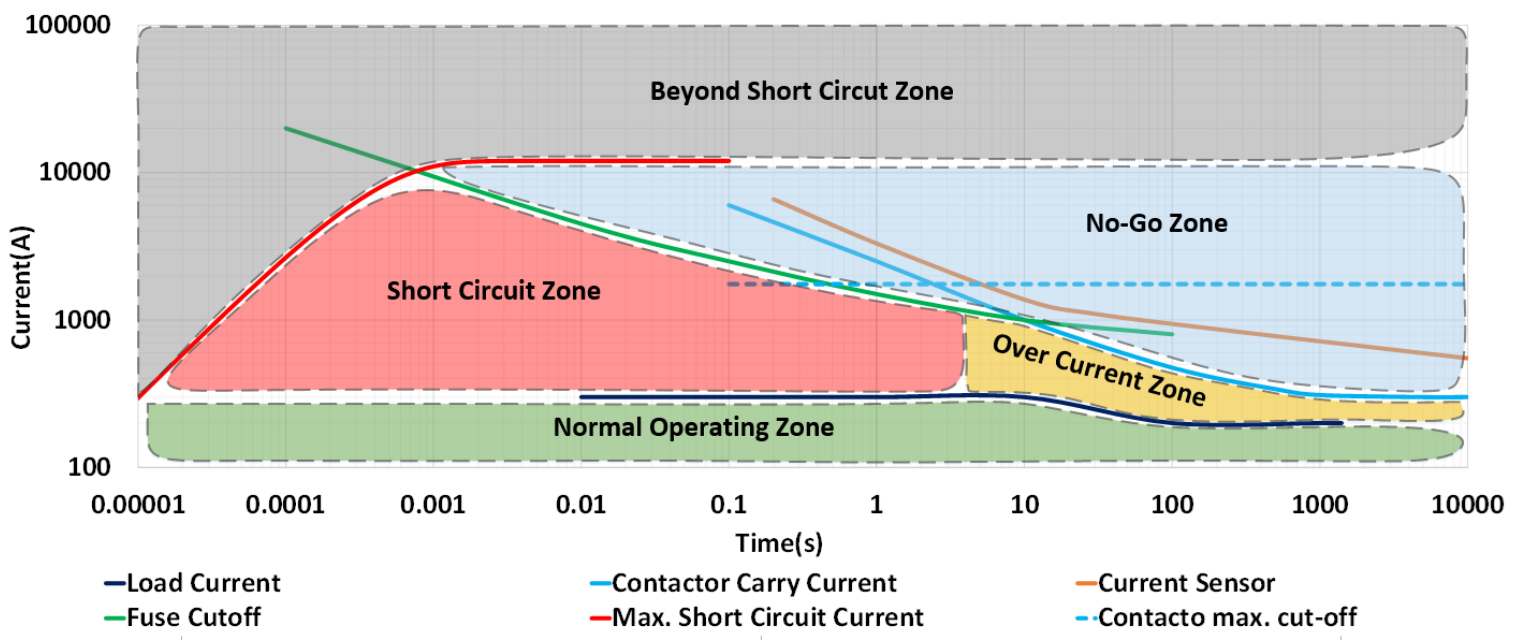

Fig. 3. Current Zones in HV Battery Pack

\section{Selective Shut-off Strategy in Distributed Battery Systems}

Selective coordination is crucial for battery system reliability. A reliable system is not only important for electrical safety but also is important from an operational perspective as battery packs will disconnect from the rest of the powertrain and stop supplying traction power to EV. This method resembles a pack safety shut-off system. As can be seen in Figure 3, in standalone packs, the I-t curves of the fuse and contactor within the maximum and minimum breaking values of these components are also important in distributed battery systems. The selective shut-off strategy addresses localizing faulted condition on the battery system and achieves a reliability design goal. A properly engineered and assembled system that's selectively coordinated will allow only the closest and proper safety component to handle a whole range of over-currents (both overloads and all fault), In this way, other packs would undisturbed. Although the battery system is limited, it will supply the required load power and preserve the continuity of vehicle operation. The one-line diagram in Figure 4 shows the structure of the strategy. In this concept, if the electrical fault occurs in pack 3 , the fault current will be cleared by safety compo- 
nents in the respected pack and the rest of the system would maintain its operation properly.

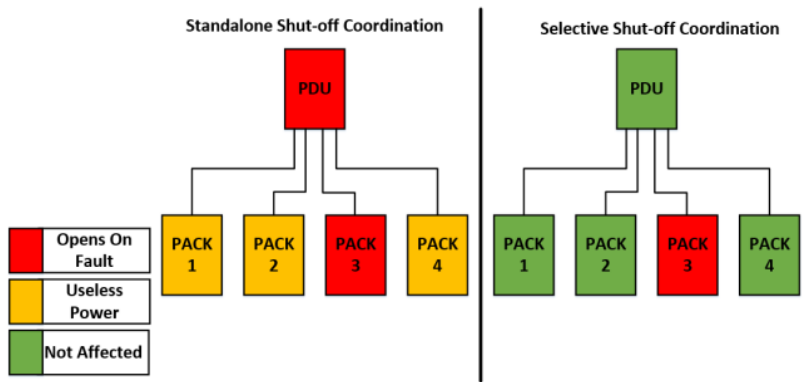

Fig. 4. Shut-off Comparison of Distributed Battery Systems

Although there are more than one selective security methods in the industry, it will be difficult to adapt a suitable one for automotive battery systems. The most convenient method is to integrate the current-time graphs of the components into the BMS algorithm and to control the system by comparing these graphs with accurate and redundant measurements from each necessary zone. To create a proper shut-off strategy, an RL equivalent circuit shall be composed of the parallel distributed battery system. Based on electric vehicle trends for the $800 \mathrm{~V}$ battery pack [24], the system is proposed with 198 series 64.6 Ah NMC cells from LG Chem to demonstrate a shut-off strategy. The proposed RL equivalent circuit is given in Figure 5 to determine the short-circuit current. Meantime, not only the maximum short-circuit current value is important but also the inductance value which affects how fast the current reaches that particular point.

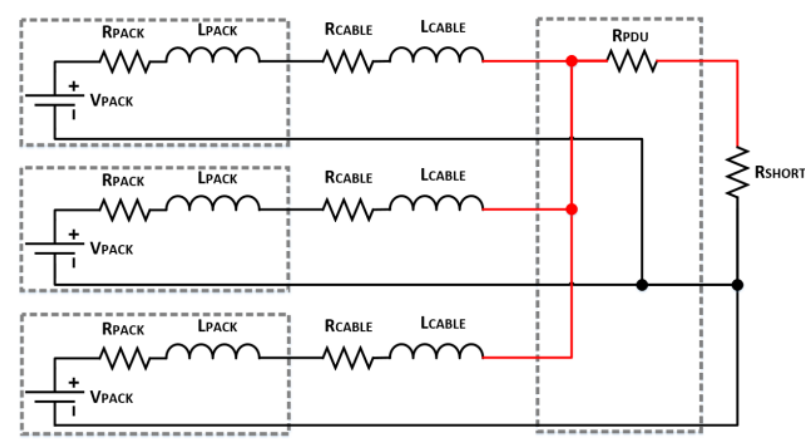

Fig. 5. RL Equivalent Circuit of Parallel DBS

RL equivalent circuit is simulated to find the short-circuit current values for the system. Moreover, the short-circuit current value per pack is extracted from the system SCC. To obtain simulation parameters, specific calculations are executed. Firstly, evaluated system parameters which are given in Table 1 are advised as legitimate specifications derived from [25].

\begin{tabular}{c|c}
\hline Capacity [Ah] & 64.6 \\
\hline Number of cells in series - $\mathrm{n}_{\mathrm{s}}$ & 198 \\
\hline Number of cells in parallel - $\mathrm{n}_{\mathrm{p}}$ & 2 \\
\hline Max. pack voltage $[\mathrm{V}]$ & 831.6 \\
\hline Inner resistance $[\mathrm{m} \Omega]-\mathrm{R}_{\mathrm{DCIR}}$ & 0.9 \\
\hline Contact resistance $[\mu \Omega]-\mathrm{R}_{\mathrm{c}}$ & 5 \\
\hline Busbar resistance $[\mathrm{m} \Omega]-\mathrm{R}_{\mathrm{B}}$ & 2 \\
\hline BDU components' resistance $[\mathrm{m} \Omega]-\mathrm{R}_{\mathrm{BDU}}$ & 0.95 \\
\hline PDU components' resistance $[\mathrm{m} \Omega]-\mathrm{R}_{\mathrm{PDU}}$ & 0.92 \\
\hline Resistance of cables $[\mathrm{m} \Omega]-\mathrm{R}_{\text {cable }}$ & 1.03 \\
\hline Additional resistance $[\mathrm{m} \Omega]-\mathrm{R}_{\text {short }}$ & 5 \\
\hline Inductance of pack $[\mu \mathrm{H}]-\mathrm{L}_{\text {pack }}$ & 30 \\
\hline Inductance of cables $[\mu \mathrm{H}]-\mathrm{L}_{\text {cable }}$ & 1 \\
\hline
\end{tabular}

Secondly, based on given parameters, equivalent pack resistance (Rpack) is calculated as $63.01 \mathrm{~m} \Omega$ with Eq. (1).

$$
R_{\text {Pack }}=\left(\left(R_{D C I R}+2 R_{C}\right) n_{s} / n_{p}\right)+R_{B}+R_{B D U}
$$

Lastly, the equivalent RL circuit is simulated with the parameters given in Table 1, and the result of Eq. (1), as a consequence of the simulation, short-circuit current characteristic of the system is obtained. Respective graphs can be seen in Figure 6.

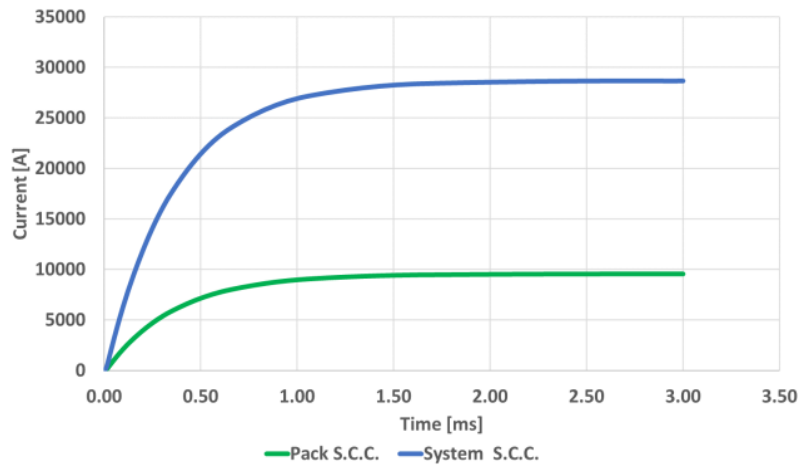

Fig. 6. SCC Characteristic of the System and Pack

By defining short-circuit current, the highest fault current that can be occurred in a system is found, in this way the upper limit of fault current is determined. On the other hand, the load profile shall be used to determine the lower limit of the fault current. Load profiles of the system and a single pack are given in Figure 7. In failure, one of the 3 packs would be short-circuited, therefore, 2 packs shall provide the required power and energy. Considering the aforementioned statement, the single pack is designed with the capability of providing half of the demanded traction load. 


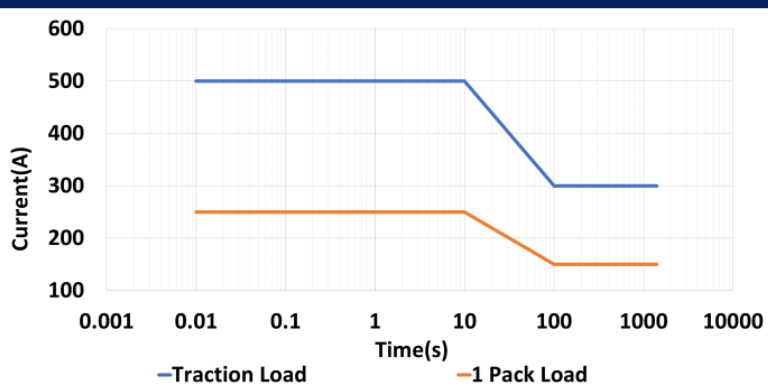

Fig. 7. Load Characteristic of the System and Pack

After the upper and lower limits are obtained, intermediate zones shall be determined. Furthermore, the most fundamental component for defining the boundaries of these zones is the fuse. Therefore, the characteristics of the fuses shall be examined in detail. Fuses are manufactured within specific tolerances and their dimensioning shall be carried out with the consideration of aging for the shut-off strategy. Although the shut-off strategy is developed with the (BOL) begin-of-life specifications of the fuse, (EOL) end-of-life conditions shall be sufficient to fulfill the normal operating boundaries. Tolerance values shall be considered over $\mathrm{I}^{2} \mathrm{t}$ because small alterations on the melting energy might affect both time and current [26]. In this concept, fuses with $10 \pm \%$ tolerance are selected for both BDU and PDU. Since early interruptions are safer than the later ones, $+10 \%$ tolerances are considered for designing the shut-off strategy, therefore, late interruptions are avoided. As a consequence, both fuses need to cover their load profiles within EOL conditions and tolerances. The current-time graph of PDU and BDU fuses are given in Figures 8.a and 8.b regarding $\mathrm{BOL}$ and $\mathrm{EOL}$ respective to tolerances.

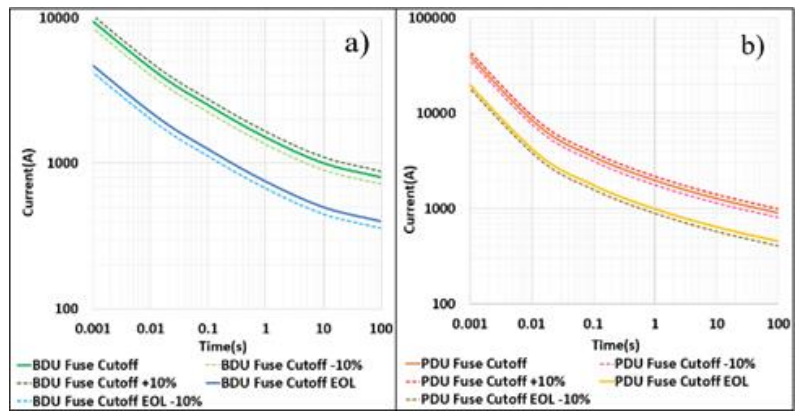

Fig. 8. a) I-t Graph of BDU Fuse b) I-t Graph of PDU Fuse

As explained in the previous section, if the curves from the contactor and current sensors are added to the fuse graphics, the regions would become clearer. The resulting regions are given in Figure 9. In the proposed concept current sensors shall measure the over-current values for the located path. Furthermore, the contactor and fuse shall have overlapping to neglect the dead-leg on the border of crossing points between the zones.

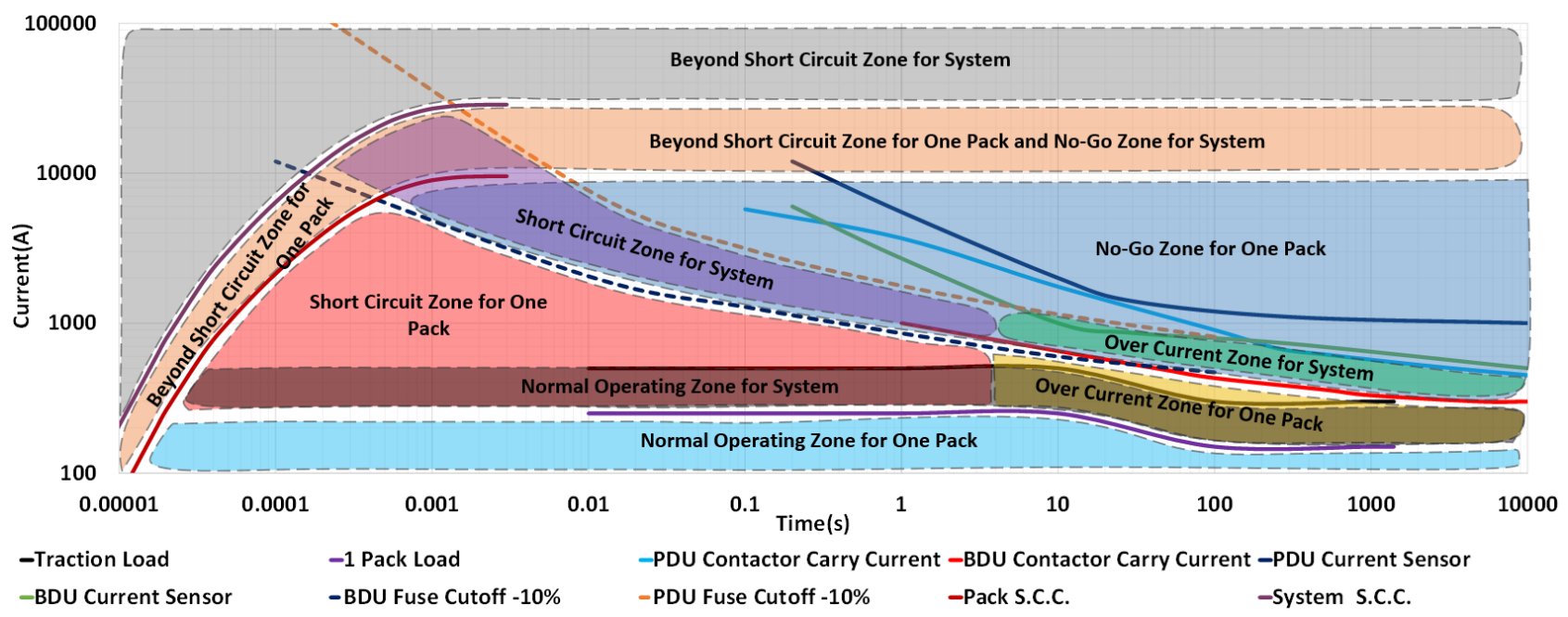

Fig. 9. Current Zones in HV Battery System

In the normal operating zone for one pack (light blue zone), all BDU and PDU components shall carry all current values without any failure. Meanwhile, only the contactors can make and break in the respected zone. The normal operating zone for the system (black zone) consists of current values identified as fault currents for the BDU, but normal operating currents for the PDU. Therefore, the components of the BDU shall interrupt in this zone while the components of PDU shall carry the current values normally. Since the current measurements are separate for the packs and the system, fault currents shall be calculated in the BMS in order to localize the proper fault zone in Figure 9, so selective protection can be provided. In the over-current zone for pack (yellow zone), the BDU contactor shall clear the fault currents, so the fuse could remain undamaged. If the current is in the short-circuit current zone for pack (red zone), the fuse shall cut-off the current and the contactor shall be kept open until the fault current is cleared. Beyond the aforementioned zones, the pack fault current cannot occur in the no-go zone for one pack (dark blue zone), due to the melting limitations of the BDU fuse. The same logic applies for the system 
fault currents, in the over-current zone for the system (green zone) PDU contactors would actuate, in the short-circuit current zone for the system (purple zone) fuse would interrupt. In addition to the dark blue zone, there is a no-go zone for the system (brown zone), in this zone, fault currents for pack and system cannot occur. The boundaries between the zones are implemented to the BMS algorithm as a lookup table, thus BMS could decide on the zones accurately. Thus, a selective shut-off strategy for distributed battery packs is achieved.

\section{Conclusion}

One of the most crucial components of the electric vehicle is the battery system which can be also a driver or barrier to electric mobility development. With the increase of high voltage packs and the emergence of DBS structures, safety studies should be carried out on such systems as in standalone battery packs. One of the most important studies that shall be concluded is overcurrent and short circuit protection. In the battery system, electrical failures may lead to thermal runaway or explosion. Handling electrical failure in the battery system brings forward the necessity of the shut-off strategy. The shut-off strategy made with contactors and fuses, realized in a conventional system, can be improved as stated in this study to provide additional advantages when it comes to DBS. The concept proposed in this study shows the sustainability of the vehicle by providing selective protection in case of failure in one of the packs in the DBS. In this study, a detailed analysis of the selective shutoff strategy for a parallel distributed battery system is investigated and protection zones are defined for both standalone pack and DBS With the guides given in this study, necessary measures shall be taken for the selection and dimensioning of switching parts (e.g., fuse, contactor). Moreover, BMS shut-off algorithm and contactor control strategy shall be improved. The main target of the strategy is to maintain the vehicle continuity in case of a failure by shuttingoff only the faulty pack instead of shutting down the whole battery system. Thus, the continuity of electric vehicles' operation can be provided with the other packs. The advantages of the system can be expanded by using pyro-fuses, smart-fuses, and even semiconductor switches. In the battery design processes, this case shall be handled carefully and evaluated at the starting of the concept phase.

\section{Acknowledgment}

This study is only funded by AVL List GmbH and AVL Araştırma ve Mühendislik Sanayi ve Ticaret Ltd. Şti. (AVL Research and Engineering Turkey)

Financial interests: The authors declare they have no financial interests

Non-financial interests: The authors are employed by AVL Araştırma ve Mühendislik Sanayi ve Ticaret Ltd. Şti. (AVL Research and Engineering Turkey)

\section{Conflict of Interest Statement}

The authors declare that there is no conflict of interest.

\section{CRediT Author Statement}

M. Kubilay Özgüç: Conceptualization, Methodology, Visualization, Kadir Aras: Writing - review \& editing

\section{References}

[1] Nazaripouya H, Wang B, Black D. Electric Vehicles and Climate Change: Additional Contribution and Improved Economic Justification. IEEE Electrification Magazine. 2019 Jun 4;7(2):33-9.

[2] Thiel C, Nijs W, Simoes S, Schmidt J, van Zyl A, Schmid E. The impact of the EU car $\mathrm{CO} 2$ regulation on the energy system and the role of electro-mobility to achieve transport decarbonisation. Energy Policy. 2016 Sep 1;96:153-66.

[3] Zhang ZJ, Fang W, Ma R. Brief review of batteries for XEV applications. eTransportation. 2019 Nov 1;2:100032.

[4] Seyitoğlu F, İşcanoğlu Y, Eren MK. BDU Topologies for Distributed Battery System in Electric Buses. In2019 11th International Conference on Electrical and Electronics Engineering (ELECO) 2019 Nov 28 (pp. 29-33). IEEE.

[5] Larsen E. A New Approach To Low-Voltage Circuit Breaker Short-Circuit Selective Coordination. In2008 IEEE/IAS Industrial and Commercial Power Systems Technical Conference 2008 May 4; (pp. 1-7). IEEE.

[6] Bussman, Cooper Industries. SPD Electrical protection handbook. Ellisville, MO: Eaton; 2018.

[7] Zhuang W, Dai J, Liu Y. Application of Solid-State Circuit Breaker in Selective Relay Protection of Marine DC Distribution System. In2019 4th IEEE Workshop on the Electronic Grid (eGRID) 2019 Nov 11 (pp. 1-6). IEEE.

[8] Miao X, Wu X, Qiu R, Chen J. Fast and selective protection technology in low voltage distribution systems. In2016 IEEE International Conference on Power and Renewable Energy (ICPRE) 2016 Oct 21 (pp. 305-309). IEEE.

[9] Laaksonen HJ. Protection Principles for Future Microgrids. IEEE Transactions on Power Electronics. 2010 Aug 16;25(12):2910-8.

[10] Sakuraba T, Ouaida R, Chen S, Chailloux T. Evaluation of Novel Hybrid Protection Based on Pyroswitch and Fuse Technologies. In2018 International Power Electronics Conference (IPEC-Niigata 2018-ECCE Asia) 2018 May 20 (pp. 2153-2157). IEEE.

[11] Lell P, Volm D. Innovative Safety Concept to Shutdown Short Circuit Currents in Battery Systems up to 1000V Based on Ultrafast Pyrofuse Technology. In2018 IEEE Holm Conference on Electrical Contacts 2018 Oct 14 (pp. 317-322). IEEE.

[12] Koprivsek M. Advanced Solutions in Over-Current Protection Of Hvdc Circuit Of Battery-Powered Electric Vehicle. InPCIM Europe 2018; International Exhibition and Conference for Power Electronics, Intelligent Motion, Renewable Energy and Energy Management 2018 Jun 5 (pp. 1-4). VDE.

[13] Koepf H, Wilkening ED, Klosinski C, Kurrat M. Breaking Performance Of Protection Devices For Automotive Dc Powertrains With A Voltage of $450 \mathrm{~V}$. InICEC 2014; The 27th International Conference on Electrical Contacts 2014 Jun 22 (pp. 1-6). VDE.

[14] Sturk D, Gustafsson P, Holgers A, Sundmark H, Cavell C, Gaudinat F, Dugast E. E-Vehicle Safety-Pyro Switch as High Voltage 
Circuit Breaker \& Bypass. In24th International Technical Conference on the Enhanced Safety of Vehicles (ESV) National Highway Traffic Safety Administration 2015 (No. 15-0163).

[15] Hsieh YC, Wu JL, Kuo QY. A Li-ion battery string protection system. In2011 International Conference on Applied Electronics 2011 Sep 7 (pp. 1-4). IEEE.

[16] Rajasekhar MV, Gorre P. High voltage battery pack design for hybrid electric vehicles. In2015 IEEE International Transportation Electrification Conference (ITEC) 2015 Aug 27 (pp. 1-7). IEEE.

[17] International Organization for Standardization. ISO 26262-3:2018. _ Road vehicles — Functional safety — Part 3: Concept phase. Geneva: ISO; 2018.

[18] Gera C, Sharma S. A Method to Diagnose Failures in High Voltage Contactors and Fuse for Safe Operation of Battery Pack. In2019 IEEE Transportation Electrification Conference (ITEC-India) 2019 Dec 17 (pp. 1-4). IEEE.

[19] Wang Z, Shi X, Tolbert LM, Wang F, Blalock BJ. A di/dt feedback-based active gate driver for smart switching and fast overcurrent protection of IGBT modules. IEEE Transactions on Power Electronics. 2013 Aug 15;29(7):3720-32.

[20] Zhou H, Ye C, Zhan X, Wang Z. Designing a SiC MOSFETs Gate Driver with High dv/dt Immunity and Rapid Short Circuit Protection for xEV Drivetrain Inverter. In2019 22nd International Conference on Electrical Machines and Systems (ICEMS) 2019 Aug 11 (pp. 1-5). IEEE.

[21] Rostaing G, Berkani M, Mechouche D, Labrousse D, Lefebvre S, Khatir Z, Dupuy P. Reliability of power MOSFET-based smart switches under normal and extreme conditions for $24 \mathrm{~V}$ battery system applications. Microelectronics Reliability. 2013 Sep 1;53(911):1703-6.

[22] Shukla A, Demetriades GD. A survey on hybrid circuit-breaker topologies. IEEE Transactions on Power Delivery. 2014 Jul 15;30(2):627-41.

[23] Meyer JM, Rufer A. A DC hybrid circuit breaker with ultra-fast contact opening and integrated gate-commutated thyristors (IGCTs). IEEE Transactions on Power Delivery. 2006 Mar 27;21(2):646-51.

[24] Jung C. Power Up with 800-V Systems: The benefits of upgrading voltage power for battery-electric passenger vehicles. IEEE Electrification Magazine. 2017 Mar 7;5(1):53-8.

[25] Ozguc MK, Ipek E, Aras K, Erhan K. Comprehensive Analysis of Pre-Charge Sequence in Automotive Battery Systems. Transactions on Environment and Electrical Engineering. 2019 Dec 25;4(1):1-6.

[26] Kulkarni M, Vaidya A, Karwa P. I2t derivation for Electrical Safety (EV). In2015 IEEE International Transportation Electrification Conference (ITEC) 2015 Aug 27 (pp. 1-3). IEEE. 